\section{Non-Euclidean Geometry.}

As many mathematicians give very little thought to the theory of sets, it is perhaps worth while dwelling for a moment on Dr. Sommerville's possibly misleading remarks in NATURE of October 5 . He, quite correctly, points out the one-one correspondence between the aggregates of integral numbers $1,2,3, \& \mathrm{c} .(n)$, and even numbers 2,4 , 6 , \&c. $(2 n)$. Thus the part appears equivalent to the whole. This statement loses the character of a paradox to all who will bear in mind that the notion of " the part cannot equal the whole" has its origin in the contemplation of finite quantities.

Again, the sets of numbers of the form $4^{n}$ and $4 n+2$ constitute aggregates of the same type; they are equivalent to each other as well as to $n$ itself and $2 n$. I fail to see that Dr. Sommerville shows the part to be larger than the whole. An aggregate $\mathrm{A}$ would be larger than $\mathrm{A}^{\prime}$ if A contained a set equivalent to $\mathrm{A}^{\prime}$, while $\mathrm{A}^{\prime}$ does not contain a set equivalent to $\mathrm{A}$.

\section{SS. Caledonia, October 14}

HaRold M. Sadow-Pittard.

IN drawing a parallel between Legendre's proof and the paradox concerning infinite aggregates, I had not thought it necessary to point out the fallacy, which consists, as in Legendre's proof, of transferring to infinities notions which are derived from a study of finite magnitudes.

Of the two propositions, a part is (1) equal to, and (2) grearer than, the whole; the one is just as much a paradox as the other until the meaning of the terms equal, greater, and less has been extended and modified for infinite aggregates; and the proofs which I gave are equally in accordance with notions derived from finite aggregates. Neither of them was intended as a valid proof, though the first happens to be in agreement with the usual extension of the meaning of equivalent. $\quad$ D. M. Y. Sommerville.

The University, St. Andrews, October 23.

\section{Dew-ponds and the Dry Season.}

WITH reference to the remark in NATURE of October 26 (p. 559), I paid a visit to the Chanctonbury Dew-pond about the end of last August, and was surprised at its flourishing condition.

The water-level was, of course, much below the normal, and the surrounding water plants were much trodden under by sheep and cattle. There still remained, however, a good fringe, and the usual pond plants seemed to be in a satisfactory state. I could not get to the water's edge owing to the moist and boggy nature of the ground, usually submerged.

Some other dew-ponds met with in the course of a few days' walk west of Chanctonbury were quite dry, so far as I remember.

University College, Reading, October 30.

\section{CHARLES DARWIN'S EARLIEST DOUBTS CONCERNING THE IMMUTABILITY OF SPECIES.}

$\mathrm{T}$ view of the great revolution in scientific thought which was inaugurated by the publication of the "Origin of Species," the story of the evolution of ideas in the mind of its author must always have a deep fascination for the student of the history of science-and the question of the nature of the initial stage of that evolution is one especially worthy of attention.

In his autobiography, Charles Darwin has declared his belief that, before leaving England for the memorable voyage in the Beagle, he was quite indifferent to any speculations upon the subject of evolution-and this in spite of his admiration for his grandfather's "Zoonomia" as a literary production." Now concerning the exact period in his life when Darwin ceased to feel this indifference, and had his interest aroused by that "mystery of mysteries" - to the solution of

$$
1 \text { "Life and Letters of Charles Darwin," vol. i., p. } 3^{8} \text {. }
$$

NO. 2 I92, VOL. 88] which his whole after-life was to be devoted-there have been very marked differences of opinion.

Huxley stated his conviction to be that no really important fruits of the observations made during the voyage of the Beagle could have been gathered by the ardent but untrained young naturalist until after he reached England, and had the opportunity of consulting specialists concerning the specimens which had been sent home by him from time to time. ${ }^{2}$ But, on the other hand, Dr. Francis Darwin and Prof. Seward maintain that during the voyage, and especially towards its close, when the Galapagos Islands were visited, Darwin's observations and his meditations upon them had already begun to bear fruit, and had led him to lose his absolute faith in the immutability of species. ${ }^{3}$ I am myself convinced, as the result of a careful consideration of letters written at the time, that very early indeed in the course of the voyage certain observations and reflections had given rise in Darwin's mind to serious misgivings concerning the fixity of species, although, writing nearly fifty years afterwards, he dismissed them lightly as nothing more than "vague doubts."

It was this statement in Darwin's correspondence to which Huxley appears to have attached very great importance. It occurs in a letter to Dr. Zacharias and is as follows :-

"When I was on board the Beagle I believed in the permanency of species, but as far as I can remember, vague doubts occasionally flitted across my mind." 4

It should be borne in mind, however, that as these lines were written as late as 1877 , to one of his very numerous casual correspondents, we may not improbably infer that Darwin penned them somewhat hastilv and without any deep thought or reflection concerning the interpretation that might be put upon them if published. For it must be remembered that nearly twenty years before this he had written and printed the following :-

"When on board H.M.S. Beagle as naturalist, I was much struck with certain facts in the distribution of the inhabitants of South America, and in the geological relations of the present to the past inhabitants of the continent." 5

Seeing that these words form the first sentence of the introduction to the "Origin of Species," and must therefore have expressed the result of very deliberate thought and consideration, that they would certainly. have been frequently scanned by the author before publication, and that they are repeated without change or qualification in every succeeding edition of the book, it is undoubtedly only fair to attach far greater weight to them than to a sentence hastily indited to a casual correspondent so many years afterwards.

In that marvel of candid introspection, the "Autobiography," Darwin wrote in 1876 as follows :-

"During the voyage of the Beagle I had been deeply. impressed by discovering in the Pampean formation great fossil animals covered with armour like that of the existing armadilloes." 6

And this he enumerates as the first, though not the most important, of the observations which turned his thoughts in the direction of evolution during the voyage. When writing to Haeckel in 1864 he savs :-

"I shall never forget my astonishment when I dug out a gigantic piece of armour like that of the armadilloes." ?

Owing to a singular blunder, for which Darwin was in no way responsible, I shall have to point out that 2 "Collected Essays," vol. ii., p. 27x.

3 "More Letters of Charles Darwin," vol. i., pp. 37-39. See alco "Foundations of the Origin of Species,", p. xv.

4 "More Letters of Charles Darwin," vol. i., p. ${ }^{5}$. The italics in this and succeeding passages are our own.

5 "Origin of Species," p. r. 6 "Life and Letters," vol. i., p. 82.

7 " History of Creation," vol, i., p. 134. 